\title{
Adenovirus-Based Gene Therapy for Cancer
}

\author{
Changqing Su \\ Department of Molecular Oncology \\ Eastern Hepatobiliary Surgical Hospital \\ The Second Military Medical University, Shanghai \\ P. R. China
}

\section{Introduction}

The concept of gene therapy is defined as a biomedical technology to treat diseases with functional genes or therapeutic genes by transferring these genes into cells. According to the most comprehensive source of information on worldwide gene therapy clinical trials available on the internet from "The Journal of Gene Medicine" clinical trial site (http://www.wiley.com/genmed/clinical), there are 1060 clinical trials (64.5\%) for cancer treatment among the total 1644 trials updated June 2010, and most of them (23.8\%) use adenovirus as vector. However, gene therapy goes through one of gains and losses since the very day of its naissance. Until late 2009, gene therapy received a series of great achievements after years of silence. The journal, Science, appraised 10 breakthroughs of the Year 2009, in which the seventh was gene therapy. It brings us a rekindled hope for overcoming the genetic diseases including cancer.

Adenoviral vectors have been used extensively in cancer gene therapy (Su et al., 2008; Yang et al., 2007). Most of them are replication-deficient (Yang, 1995). The first generated replication-deficient adenovirus lacks the E1 and E3 regions. The second and third ones also contain E2 and/or E4 deletions (Andrews et al., 2001; Thomas et al., 2003). Because the replication-deficient adenoviruses can not replicate, they express the foreign therapeutic genes only in the cells that are initially infected. Synchronously, they also lack a specificity target to cancer cells (Kurihara et al., 2000). These problems may decrease the therapeutic effect on cancer cells and result in toxicity to normal cells. Therefore, development of a novel tumor-targeting adenoviral vector is needed to enhance the efficiency and specificity of transgene expression. Oncolytic adenoviruses are promising as therapeutic agents in cancer treatment. These viruses are genetically modified to target, infect and replicate in cancer cells causing them to lyse with an improved, superior efficacy compared to non-replicating adenoviral vector which lacks the E1 genes. Here, combined with the studies of our group (Fang et al., 2009, 2010; He et al., 2009, 2010; Hu et al., 2010; Ma et al., 2009; Su et al., 2004, 2006a, 2006b, 2008a, 2008b), we review the development of oncolytic adenovirus-based gene therapy for cancer, and figured the potential prospects of gene therapy in cancer treatment.

\section{Adenovirus gene therapy}

The strategy of virotherapy, a method for the treatment of cancer with viruses, has been revitalized since the appearance of a series of novel conditionally replicating adenoviruses 
(CRAds), also known as oncolytic adenoviruses (Alemany et al., 2000). These tumorselective replicating viruses were designed to replicate preferentially in cancer cells, but not in normal cells. The infection, replication and oncolytic abilities of CRAds were targeted specifically to cancer cells and had little or no influence on the normal cells (Kirn et al., 2001). After infecting one cancer cell and replicating in it, the viruses replicate and lyse the infected cell, and the progeny virions are released and infect the rest neighboring cancer cells. These cycles of infections and replications carry on repeatedly, making a chain reaction to facilitate viral spread within the cancer tissues till all cancer cells are destroyed (Ramachandra et al., 2001).

As antitumor therapeutic agents, CRAds are accordingly armed with incontestable advantages and is superior to replication-deficient adenovirus. There are a number of ongoing preclinical or clinical trials with oncolytic adenoviruses in treatment of a variety of cancers, such as OBP-301 (Telomelysin) in lung and prostate cancers, Ad-d1922-947, AdOnyx-015, Ad-Onyx-017, Ad-vKH1 and AdEHE2F in breast, colon, head and neck cancers (Bazan-Peregrino et al., 2008; Ouchi et al., 2009). A product of Onyx Pharmaceuticals (Richmond, CA), ONYX-015, is a replicative virus studied in clinical trials for several years. It is a chimeric human group $\mathrm{C}$ adenovirus ( $\mathrm{Ad} 2$ and $\mathrm{Ad} 5$ ) modified by deletion between nucleotides 2496 and 3323 in the E1B region encoding the 55-kDa protein which binds the tumor suppressor protein p53. ONYX-015 has an ability to selectively replicate in and kill many human malignant tumor cells with mutations of p53 gene (Bischoff et al., 1996; Khuri et al., 2000).

Although the replicative viruses have many advantages to exert antitumor efficacy, they also have limitations in cancer therapy. Durable responses in clinical trials with replicative viruses, including ONYX-015, as single oncolytic agents have not been very encouraging (Ganly et al., 2000). It is not unexpected that a virus utilizing one of many mechanisms, such as p53 pathway, to promote its replication does not have enough power to destroy all cancer cells. This intrinsic limitation of targeted therapies mandates devotion to developing a series of selectively replicating viruses targeted to different tumorigenesis pathways, and to refining on replicative viruses with higher specificity, lower toxicity and stronger oncolytic efficacy for different tumors and different patients.

In order that viruses will specifically infect cancer cells, and the viral replication can be carefully controlled for the purpose of killing cancer cells safely and effectively, a cancerspecific expression and transportation system is required. One attempt to achieve CRAd is to modify adenovirus by partial deletion of viral genes (Biederer et al., 2002; Ring, 2002). The representative of this type of CRAd is ONYX-015. Moreover, many cancers have their own special markers whose expression is controlled by the particular cis-acting elements and trans-acting factors. Another attempt to achieve CRAd is to place viral replicative genes under the control of cancer-specific promoters. Although these tissue- or cancer-specific promoters can provide the restricted viral replication in cancer cells by controlling the expression of viral replicative genes, their shortcomings are obvious and cannot be ignored. Firstly, they are limited to a narrow range of cancers expressing the targeted tumor markers, and cannot be used for treatment of cancers of different origins. Secondly, most of them are much weaker than commonly used viral promoters such as cytomegalovirus (CMV) or SV40 early promoter ( $\mathrm{Gu}$ et al., 2002). The expression of the genes driven by these specific promoters is generally in lower levels, thus attenuating their effects in cancer therapy (Su et al., 2004). 
Many attempts have been made to improve both the antitumor potency and biosafety of approaches combining viral oncolytic therapy and transgene therapy. Genetic reengineering of CRAds by incorporating therapeutic payloads may yield mutually supportive antitumor effects. CRAd replication selectively amplifies therapeutic transgene expression in cancer cells (Haviv et al., 2001; Nanda et al., 2001), and transgene expression synchronously increases the spread of viral progeny within a tumor cell mass (Hermiston \& Kuhn, 2002; Van Beusechem et al., 2002). It has been shown that the approach combining gene therapy with oncolytic virotherapy is more effective than their use individually. Many therapeutic transgenes have exhibited antitumor efficacy in experimental models, including cytotoxic genes, suicide genes, tumor suppressor genes, apoptosis-inducing genes, angiogenesis-inhibiting genes and immunostimulatory genes (Haviv \& Curiel, 2003; Lam \& Breakefield, 2001). Some strategies have employed CRAds armed with immunostimulatory genes to enhance their overall antitumor activity. Heat shock proteins (HSPs) play important roles in eliciting innate and adaptive immunity by chaperoning peptides for antigen presentation to antigen-presenting cells and providing endogenous danger signalling. The recombinant oncolytic adenoviruses overexpressing the HSP70 protein can accordingly eradicate primary tumors, as well as inhibit the growth of established metastatic tumors in mice as a result of their capacity to induce individual tumor-specific immune responses (Huang et al., 2003). Although a few achievements have recently been made in the field of cancer gene therapy, great effort is still needed to select effective transgenes with more efficacy against cancers, and modify adenoviral vectors with more biosafety and specificity (Su et al., 2006a).

\subsection{Modification of adenovirus E1a gene for CRAds}

CRAds are genetically modified to express the wild type of E1a (wE1a) and showed good cytolytic effect in various human cancers (Hong et al., 2008; Liao et al., 2007; Su et al., 2006b, 2008a, 2008b), which binds to cellular regulators and mediates a series of genetic events, for instance, suppression of transformation, tumorigenicity and cancer metastatic ability (Kim et al., 2007). In addition, the E1a antitumor effect may be involved in many genetic factors in cancer cells, including E1a-induced apoptosis (Radke et al., 2008), Ela-enhanced sensitivity to chemotherapeutics and radiation (Sánchez-Prieto et al., 1996), E1a-triggered accumulation of p53 product and the E1a-mediated down-regulation of the oncogene Neu (ErbB-2/HER2) expression (Bartholomeusz et al., 2005; Madhusudan et al., 2004). Neu protein is a member of epidermal growth factor receptor (EGFR) and is commonly overexpressed in many human solid cancers, eg. in breast and primary liver cancer. E1a-mediated down-regulation of Neu expression in cancer cells could inhibit cancer cell proliferation and progression. Indeed, E1a-targeted gene therapy has been tested in clinical trials in cancer patients (Yoo et al., 2001). Moreover, during adenovirus infection, E1a protein interacts with a number of cellular proteins, thereby has an important role in facilitating viral replication.

The wE1a protein consists of three conserved regions (CR1, CR2, and CR3). These regions have different functions for viral antitumor effect and its replication. CR1 and CR2 are known to act through several cellular transcription factors, such as E2F, AP1, ATF, ETF, Sp1, $\mathrm{CBP} / \mathrm{p} 300, \mathrm{P} / \mathrm{CAF}$, and USF, that interact with E1a-inducible promoters (Hale \& Braithwaite, 1999). The N-terminus of CR1 is also required for the transcriptional activation, expression and stability of p53, and induces p53-dependent apoptosis (Itamochi et al., 2007). The CR2 domain binds to retinoblastoma tumor suppressor $(\mathrm{Rb})$ protein, resulting in an inhibition of E2F transcription factors, and activating genes for cell cycle progression (Berk, 
2005). The CR3 is a transcriptional activation domain that associates with CtIP, Sur2, CtBP (Bruton et al., 2007, 2008). However, any modification of the E1a gene which would optimise its antitumor efficacy without any significant negative effect on viral replication still needs to be investigated.

For increasing the $w E 1 a$ antitumor efficacy without decreasing its effect on viral replication, the 870-bp wE1a gene was modified by deleting parts of the E1a CR2 (amino acid residues 125 to 128) and CR3 (amino acid residues 140 to 185) to yield a novel 720-bp truncated minimal-E1a gene (mE1a). The mE1a gene was introduced into an oncolytic adenoviral vector lacking the E1b genes, placing it under the control of human telomerase reverse transcriptase (hTERT) promoter, creating AdDC315-mE1a. The experiments showed that the vector was shown to give a high expression of mE1a protein in all cancer cell lines tested, including HepGII, A549, SGC-7901, Hela, MCF-7, HT-29, and also in HepGII xenograft models in nude mice where the expression was stable throughout the experiment ( 35 days). In AdDC315-mE1a treated cell lines and the xenografted tumors, the mE1a protein expression was selective in various cancer cell lines, but expression was negative or only weakly positive in the normal cells (Fang et al., 2009).

The truncated mE1a gene was also proved to have capacities to down-regulate Neu expression, and also support adenoviral replication for the oncolytic vector as well as the wE1a gene. But there is a difference between the mE1a gene and wE1a gene, the mE1a gene can release $\mathrm{Rb}$ protein efficiently and preserve the $\mathrm{Rb}$ function. The $\mathrm{Rb}$ pathway is frequently defective by phosphorylation of $\mathrm{Rb}$ protein $(\mathrm{pRb})$. When the cancer cells are infected with adenoviruses, the $\mathrm{Rb}$ protein also can be inactivated by combination with the E1a-CR2 domains (Nemajerova et al., 2008). Both the phosphorylation and combination of $\mathrm{Rb}$ protein resulted in the release of E2F factor, thus the E2F activity is high in cancer cells. The oncolytic adenovirus with a deletion of $24 \mathrm{bp}$ in Rb-binding region of the E1a protein (amino acids 122-129) is sufficient to prevent binding to and inactivation of the $\mathrm{Rb}$ protein, but it has little effect on the functions of the E1a protein that are necessary for effective viral replication in cancer cells (Fueyo et al., 2000). The results demonstrated that the mE1a gene with a small deletion of 125-128 amino acid residules in $\mathrm{Rb}$-binding region has a diminished binding affinity to $\mathrm{Rb}$ and can preserve $\mathrm{Rb}$ function.

The adenovirus E1a can render the adenovirus-infected cells susceptible to DNA damage from chemotherapy and radiation. Interestingly, normal cells appear to be unaffected by E1a protein (Sánchez-Prieto et al., 1996). Most oncolytic adenoviruses have been engineered by holding E1a gene expression. Thereby, in addition to their oncolytic effects, E1a protein endows oncolytic adenovirus with higher antitumor potency. Since the 1990s, oncolytic adenoviruses with E1a expression were utilized to treat cancer patients from Phase I to Phase III. In 2004, China approved one kind of oncolytic adenovirus, H101, to market. Clinical data showed that H101 is well tolerable and has good efficacy when combined with chemotherapy in some cancer treatment modalities (Yu \& Fang, 2007). For the purpose of optimizing the therapeutic efficacy of wE1a, the small truncated E1a variant, mE1A, is proved to be capable of down-regulating Neu expression and supporting adenovirus replication in the mE1a-expressed cancer cells. It has a particular strongpoint to boost $\mathrm{Rb}$ function differed from the wE1a gene. Thereby, the mE1a-supported oncolytic adenovirus is endowed with more effective effects on tumor growth suppression, cell cycle arrest and cancer cell apoptosis as demonstrated in hepatocarcinoma xenografts in nude mice (Fang et al., 2009). 


\subsection{Modification of tumor-selective promoters for CRAds}

Several tissue- and cell-specific promoters that are more active in the particular cancer cells, but inactive or only weakly active in the cancer-originating somatic cells, have been identified and exploited to construct CRAds or target gene transportation and expression in cancers, such as the carcinoembryonic antigen (CEA) promoter in colorectal and lung cancer (Osaki et al., 1994), the DF3/MUC1 antigen promoter in breast cancer (Kurihara et al., 2000), the E2F transcriptional factor promoter in cancers with a defective $\mathrm{pRb} / \mathrm{E} 2 \mathrm{~F} / \mathrm{p} 16$ pathway (Johnson et al., 2002; Ramachandra et al., 2001; Tsukuda et al., 2002), the a-fetoprotein promoter in hepatocellular cancer (Ohashi et al., 2001), the prostate-specific antigen (PSA) promoter in prostate cancer (Rodriguez et al., 1997) and the L-plastin promoter in ovarian and bladder cancers (Peng et al., 2001). These cancer-specific promoters can provide CRAds the selective replication in corresponding cancer cells and demonstrate antitumor activity in preclinical models and clinical trials. However, most of them limit to target a narrow range of cancers expressing the corresponding tumor antigen, thus attenuating their efficacy in cancer therapy. More efforts should be put in seek the tumor-selective promoters targeting a wide range of human cancers.

\subsubsection{The hTERT promoter-regulated CRAds}

A number of gene therapeutic approaches have been proposed to kill cancer cells or inhibit growth of caners by targeting telomerase (Hodes, 2001). Telomerase, a unique enzyme that synthesizes telomeric repeats, is highly activated in immortalized cell lines and most of the malignant tumors, but is inactive in normal somatic cells (Cong et al., 1999; Kim et al., 1994; Shay \& Bacchetti, 1997). Telomerase activation has been regarded as a crucial step in cellular carcinogenesis, and it is the broadest spectrum molecular marker of malignancies found. More detailed analyses of telomerase activity in normal and malignant cells suggested that telomerase is active in most cancers, more than $85 \%$ of human primary cancers exhibit telomerase activity (Nowak et al., 2003; Saretzki et al., 2002), but not in normal tissues except hematopoietic stem cells and germ cells in the ovary and testis (Kim et al., 1994; Yui et al., 1998). With these properties, telomerase is an ideal target for cancer gene therapy and has attracted an intense interest in recent years. The studies have established a possibility that the manipulation of telomerase function may have an important role in cancer therapeutic intervention. Based on the knowledge on the structure and function of telomere and telomerase, a number of approaches have been proposed to inhibit the growth and division of caner cells by targeting the telomerase (Hodes, 2001).

Telomerase is a ribonucleoprotein complex composed of the telomerase RNA (hTR), the telomerase associated protein and the telomerase reverse transcriptase (hTERT). By cloning of the hTR and hTERT components to clarify the mechanism of telomerase activation, it has been demonstrated that hTR is expressed in both telomerase-positive and -negative cells, but hTERT is expressed only in telomerase-positive cells but not in telomerase-negative cells. Transferring hTERT gene into telomerase-negative cells can induce telomerase activation in these cells (Nakayama et al., 1998; Weinrich et al., 1997). A strong correlation is established between hTERT expression and telomerase activity. These findings strongly suggest that the hTERT component is the key determinant of human telomerase activity, and utilizing hTERT promoter to drive antitumoral genes in cancer gene therapy can target to and selectively kill the cancer cells with positive telomerase activity, without affecting the normal cells with negative telomerase activity (Koga et al., 2000; Poole et al., 2001). 
The hTERT promoter has been cloned and identified (Cong et al., 1999; Horikawa et al., 1999). It is highly G/C-rich and lacks TATA and CAAT boxes, and has several binding sites for transcriptional factors, including the transcriptional activating factors Myc (Eickbush, 1997), SP1 (Kyo et al., 2000), and the transcriptional repressing factors Mad1 (Gunes et al., 2000), p53 (Xu et al., 2000), MZF2 (Fujimoto et al., 2000). By measuring the transcriptional activity of a series of constructs containing unidirectionally deleted fragments of the hTERT promoter, some investigators discovered that a $181 \mathrm{bp}$ fragment upstream of the transcriptional start site is the smallest core promoter essential for transcriptional activation of hTERT gene (Abdul-Ghani et al., 2000; Takakura et al., 1999). The expression of c-Myc oncoprotein markedly induces the transcriptional activity of the hTERT promoter in the endogenous hTERT-negative cells, and induces 3- to 7-fold increase of the hTERT promoter activity in the hTERT-positive cell lines (Horikawa et al., 1999). The mechanism of c-Myc protein up-regulating the hTERT promoter activity is probably through the E-box motifs (CACGTG) within the hTERT core promoter. It has been shown that although SP1 factor is over-expressed in the telomerase-negative normal somatic cells and its binding to the specific sites promotes the start of hTERT gene transcription, by comparison, the major determinant regulating the hTERT gene expression is the transcriptional factors that combined with E-box motifs. In addition to the E-box (-187 bp to $-182 \mathrm{bp}$ ) upstream of the transcriptional start site (Horikawa et al., 1999), there is another E-box (+22 bp to $+27 \mathrm{bp}$ ) downstream of the transcriptional start site (Horikawa et al., 2002). This downstream E-box mediates the activation or repression of hTERT gene transcription by binding c-Myc or Mad1 transcriptional factors, respectively (Greenberg et al., 1999; Gunes et al., 2000). The current research demonstrated that the downstream E-box is a target for down-regulating the hTERT activity in the telomerase-negative cells. But this downstream E-box changes to the binding site for up-regulating the hTERT gene transcription in the telomerase-positive cells when it combines with the transcriptional activating factors such as the upstream stimulatory factor (USF), a member of Myc family (Horikawa et al., 2002). Therefore, the expression of the hTERT gene determining the telomerase activity is firmly controlled by many factors including the transcriptional activating and repressing factors, and the regulatory sites mainly locate in the promoter region of the hTERT gene.

Some current studies showed that the hTERT promoter which was used to construct CRAds by controlling the E1a gene demonstrated a sufficient activity for viral effective replication in cancer cells (Huang et al., 2003; Irving et al., 2004; Kawashima et al., 2004; Zou et al., 2004). To further improve the specificity of hTERT promoter, the activity of hTERT core promoter could be enhanced significantly in the majority of the cancer cell lines by inserting the adenovirus E1a TATA box downstream of the hTERT promoter (Wirth et al., 2003). A CRAd, CNHK300, in which the hTERT promoter is used to replace the original regulatory elements of E1a gene and to control the E1a gene expression, can target to the telomerasepositive cancer cells and replicate in them, resulting in oncolysis, when the progeny virions are released and infect the adjacent cancer cells, they will not affect the normal cells negative for telomerase activity. Another interesting approach developed an oncolytic adenovirus AdEHT2 in which a minimal dual-specificity promoter that responds to estrogens and hypoxia was used to control the viral E1a gene, and the hTERT core promoter was introduced into the E4 region of AdEHT2 (Hernandez-Alcoceba et al., 2002). Their experiments of viral replication and cytotoxicity showed that AdEHT2 was not attenuated in telomerase-negative cells when these cells were infected under hypoxia conditions. It was postulated that the good expression of the adenoviral E1a gene activated by hypoxia was 
sufficient to promote the viral replication. They also held that the E1a protein can potentially stimulate the hTERT promoter in the E4 region directly or as a consequence of the cell cycle activation. Although the E4-deleted adenovirus was attenuated, a low level of the E4 open reading frame expression could support its replication under the condition that the rest transcriptional units of the virus were activated. Based on the published data and the current study, it is reasonable to conclude that the tight regulation of the adenoviral E1a gene is crucial for the replication of the virus.

One of the major concerns was the potential toxicity of hTERT promoter-regulated CRAds to stem cells or other normal cells, although there were evidences suggesting that the toxic effects caused by the use of the hTERT promoter on normal cells may be transient (Chiu et al., 1996), and could be prevented by using the adenoviral vectors which infect stem cells poorly (Gu et al., 2000). The toxicity assay was performed in BALB/c mice by sequential intravenous injections of the hTERT promoter-regulated CRAds and the control virus (wild adenovirus type 5, wAd5). The main objective is to investigate whether the replicative adenovirus has toxicity to liver cells after systemic delivery. The results suggested that the hTERT promoter-regulated CRAds are less toxic than wAd5 after intravenous administration. They are well tolerated at a low dosage that was equal to the therapeutic dosage for the treatment of the transplantation tumors of nude mice. Even at a high dosage of hTERT promoter-regulated CRAds, mice showed no signs of toxicity in terms of mortality, liver enzyme levels and hepatocyte morphology, no replication of viruses was found in liver tissues by E1a immunohistochemistry, and only slight granular or hydropic degeneration of hepatocytes could be observed. Meanwhile, wAd5 displayed both a certain mortality and liver toxicity. All mice died at a high dosage of wAd5, and the therapeutic dosage induced an obvious increase of liver enzymes and evidence of cytopathic effects on liver tissues. Therefore, the toxic effect of hTERT promoter-regulated CRAds is much weakened compared with wAd5 by the use of the hTERT promoter (Su et al., 2004, 2006b, 2008a; Wang et al., 2008).

\subsubsection{The E2F promoter-regulated CRAds}

The loose control of cell cycle is a key feature of cancer cell proliferation. Much evidence suggests that the Cyclin/Cyclin-dependent kinase (CDK)/P16/retinoblastoma protein $(\mathrm{Rb}) / \mathrm{E} 2 \mathrm{~F}$ pathway is the major link for cell cycle control. Cyclin D1 activates CDK4 and promotes the phosphorylation of $\mathrm{Rb}$ protein, which makes the $\mathrm{E} 2 \mathrm{~F}$ transcriptional factor released from Rb-E2F complex. Then the E2F transcriptional factor activates the transcription of many important cell cycle regulatory genes, and promotes tumorigenesis. P16 is known as a negative regulator of cell cycle, which can block cell cycle progression from G1 to S phase by binding to CDK4 and inhibiting the action of Cyclin D1 (Coqueret, 2002; Ortega et al., 2002). It was found that the inactivation of Cyclin D/ CDK/ P16/ Rb/ E2F pathway is a common characteristic of most solid cancers (Gemin et al., 2005; Johnson et al., 2002; Tsukuda et al., 2002). This pathway is an ideal target for cancer gene therapy and has attracted an intense interest in recent years.

As described above, cancer cells with the deficiency of Cyclin /CDK/P16/Rb/E2F pathway have high activity of E2F transcriptional factor, thus this important factor is defined as a crucial target in cancer treatment. A CRAd, AdEHE2F, in which the expression of E4 gene is controlled by the E2F promoter, had been generated for breast cancer treatment (Post et al., 2003). The tight regulation of E4 expression correlated with the viral ability to selectively replicate and kill cancer cells. Current study constructed an E2F promoter-regulated CRAd 
which was armed with the p16 gene, AdE2F-p16. By controlling the E1a gene expression with the E2F promoter, AdE2F-p16 achieved a desired specificity to target cancer cells, while the normal cells were spared. The luciferase assay suggested that the E2F promoter had a high activity in cancer cells but not in normal cells. The data from in vitro experiments showed that AdE2F-p16 specifically replicated and induced E1a expression in cancer cells. Due to the viral replication, AdE2F-p16 more efficiently expressed P16 than the replicationdeficient adenovirus AdCMV-p16 in cancer cells. Thereby, AdE2F-p16 overcomes the disadvantages of low transfer rate and poor gene expression compared with the replicationdeficient adenovirus vectors. In summary, the E2F promoter-regulated, p16-armed CRAd can mediate the effective expression of transgene in cancer cells, and displays a satisfactory therapeutic effect for cancer (Ma et al., 2009).

To further investigate the molecular mechanisms of P16-induced apoptosis, the consequential study found that the adenovirus-mediated P16 reactivation lead to an inhibition of Akt signaling pathway and a downregulation of survivin expression in hepatocellular carcinoma cells (Hu et al., 2010). P16 and survivin are a pair of incompatible factors in the cell cycle and cell apoptosis regulation. Cyclin D1 and P16 eventually regulate cell cycle by interacting with CDK4 (Ai et al., 2005). CDK4 and survivin are co-localized mainly in nuclei of the P16-deficient hepatocellular carcinoma cells. But when cancer cells re-express P16, the P16 protein competes with survivin for CDK4 binding and transports CDK4 from nuclei to cytoplasm. The translocation of CDK4 from nuclei to cytoplasm illuminates that its function to accelerate cell proliferation is weakened. Interestingly, it is found an important molecular event that the nuclear survivin is reduced obviously in cancer cells after P16 re-expressed. The localization of survivin in cancer cells exerts different functions. The nuclear survivin is involved in promoting cell proliferation, whereas the cytoplasmic survivin may participate in controlling cell survival (Connell et al., 2008; Li et al., 2005; Liu \& Matsuura, 2005). Accordingly, survivin promotes cell proliferation and inhibits cell apoptosis by competitively interacting with CDK4, and the P16-induced decrease of the amount of survivin and CDK4 in nuclei contributes to the inhibition of cell cycle progression and induction of detachment-induced apoptosis (anoikis) in cancer cells. This new insight into P16 function would help in designing better strategies for cancer gene therapy.

\subsection{Utilization of antitumor transgenes}

CRAds can be designed to function as therapeutic gene delivery vehicles by incorporating antitumor transgenes, and their antitumor efficacy is thus increased by the combination of antitumor gene therapy and oncolytic viral therapy (Chen et al., 2005; Nagayama et al., 2003; Post et al., 2003; Su et al., 2006a). Previous studies confirmed the antitumor activity of various vectors carrying cytokine genes, such as interferons (Belardelli \& Gresser, 1996), tumor necrosis factors (Zhang et al., 1996), drug-sensitive gene HSV-tk (Steele, 2000), antiangiogenesis genes (Fang et al., 2010). When these therapeutic genes were inserted into the genome of CRAds, they were selectively and highly expressed in cancer cells as a result of the cancer-selective replication of CARds, which further enhanced therapeutic effect targeting cancer cells without toxicity to normal tissues or cells.

\subsubsection{CRAd with interferon-gamma (IFN-y) gene}

Interferons (IFNs) are the first cytokines to be applied clinically in treatment of human cancers, and have anti-proliferative effects and immune modulatory activity. They have also 
been shown to inhibit angiogenesis and suppress tumor vascularization (Dvorak \& Gresser, 1989; Fathallah-Shaykh et al., 2000; Singh et al., 1995). Among IFNs, IFN- $\gamma$ is vital to the promotion of tumor surveillance in immunocompetent hosts and activates macrophages to nonspecifically lyse cancer cells through various mechanisms (Baratin et al., 2001; Guadagni et al., 1994). IFN- $\gamma$ can enhance antitumor immune response by upregulating major histocompatibility complex class I expression and accentuating the migration of specific and non-specific immune cells to necrotic areas which develop spontaneously in large tumors (Khorana et al., 2003; Merritt et al., 2004; Peyregne et al., 2004). Gene transfer of IFN- $\gamma$ inhibits neovascularization of tumors by inducing apoptosis of endothelial cells (Kowalczyk et al., 2003), suggesting that IFN-ץ represses tumor growth by the dual mechanisms of inhibition of angiogenesis and elicitation of an immunotherapeutic response.

In clinical trials, only high concentration of IFN- $\gamma$ product in tumor tissues yields antiangiogenic effects and immune response. Unfortunately, high concentration of IFN- $\gamma$ product is associated with significant toxic effects, including fever, endocrine dysfunction, thrombocytopenia, and hepatic toxicity (Jonasch \& Haluska, 2001). Therefore, its toxicity limits the administration of high concentration of this agent. Based on dual antitumor features of the IFN- $\gamma$ gene and tumor-selective replication of viruses, CRAds armed with the IFN- $\gamma$ gene could amplify transgene copies in tumor cells and produce high local concentration of IFN- $\gamma$ product in tumor tissues. This strategy could thus yield multiple antitumor effects including oncolysis, antiangiogenesis, and induction of immune response. Even in immunodeficient animals, delivery of IFN- $\gamma$ can partially restore significant immune activity (Wu et al., 2001).

In tumor models of nude mice, the IFN- $\gamma$ gene-armed CRAd exhibited efficient antitumor activity against tumor xenografts. Many extensive foci of necrosis appeared in virus-treated tumor specimens. Around the necrotic foci, there were cancer cells positive for adenoviral capsid protein in tumor tissues, suggesting the selective replication and oncolytic effect of the IFN- $\gamma$ gene-armed CRAd in cancer cells. The number of microvessels was clearly decreased in tumor tissues, which may be one of the mechanisms of IFN- $\gamma$-mediated antitumor responses in mice. Since suppressing tumor angiogenesis could lead to tumor starvation and regression (Folkman, 1998), decreasing the number of microvessels in tumor tissues might strongly suppress tumor growth. The present study found that more effective antitumor immune responses were exhibited when the IFN- $\gamma$ gene-armed CRAd was used in immunocompetent hosts than in immunodeficient animals, because the host immune system was intact to support the full function of IFN- $\gamma$. After treated with the IFN- $\gamma$ gene-armed CRAd, the increase in numbers of LCA+, CD4+, and CD8+ lymphocytes and the ratio of CD4+/CD8+ in tumor tissues accounted for the enhancement of immune responses to cancer cells (Su et al., 2006a). It is hypothesized that the combination of oncolytic virotherapy and immune gene therapy would enhance antitumor efficacy in both immunodeficient and immunocompetent hosts, and obtained results strongly supporting this hypothesis.

\subsubsection{CRAd with antiangiogenesis gene}

Increasing evidence suggests that the solid tumors and their metastasis are angiogenesis dependent. Angiogenesis is a complex process that includes the activation, proliferation, and migration of endothelial cells. This process involves in the formation of vascular tubes and networks. Antiangiogenic therapy attempts to stop new microvessels from forming around tumors and to break up the existing network of abnormal capillaries that feed the cancerous mass, finally mediates the inhibition of cancer growth. 
Endostatin, a 20-kDa C-terminal fragment of collagen XVIII, is the most potent angiogenesis inhibitor and specifically inhibits endothelial cell proliferation and migration, induces apoptosis of vascular endothelial cells (Lai et al., 2007; Li et al., 2008; Ning et al., 2008), and has been demonstrated to be with antitumor effect in many solid tumors, and without toxicity, immunogenesis or resistance. The adenovirus vector carrying a secretable form of mouse endostatin, Av3mEndo, mediated the secreted expression of endostatin from Av3mEndo-transduced mammalian cells and showed a potential inhibition of endothelial cell migration in vitro. A single intravenous administration of Av3mEndo in mice could result in prolonged and elevated levels of circulating endostatin, partial inhibition of vascular endothelial growth factor (VEGF)-induced angiogenesis, and in $25 \%$ of mice the complete prevention of tumor growth (Chen et al., 2000). The CRAd, AdSu-hE, in which a chimeric promoter of HER2 enhancer and hTERT promoter was used to drive the E1a gene, a cytomegalovirus promoter to control the human endostatin gene. In vivo intratumoral delivery of the CRAd to pre-established hepatocellular carcinoma tumors in nude mice induced a significant tumor reduction and, in some cases resulted in a complete tumor regression (Fang et al., 2010).

Canstatin, a novel matrix-derived inhibitor of angiogenesis, was described as being at least 10-fold more active than endostatin (Kamphaus et al., 2000; Narazaki \& Tosato, 2006). Experiments demonstrated that recombinant canstatin can potently inhibit endothelial cell proliferation, migration, and induce apoptosis in vitro. Moreover, it can successfully suppress the growth of implanted human xenografts of renal cell carcinoma and prostate tumors through antiangiogenesis effect (Kamphaus et al., 2000). The canstatin gene was inserted into an E1B-55kDa-deleted adenovirus vector and constructed an adenovirus, CRAd-Cans. It showed markedly improved inhibitory effects on the growth of the pancreatic cancer in mice with a prolonged survival rate through the mechanisms of oncolytic and anti-angiogenesis effects (He et al., 2009).

\subsubsection{CRAd with tumor suppression gene}

P16 is known as a negative regulator of cell cycle, which can block cell cycle progression from G1 to S phase by binding to CDK4 and inhibiting the action of Cyclin D1 (Canepa et al., 2007; Coqueret, 2002). It was found that the P16 inactivation is a frequent molecular event in most cancers. The mechanisms of P16 inactivation include the homozygous deletion, point mutation and 5'-CpG island methylation (Ortega et al., 2002). Due to the P16 inactivation, cancer cells show growth superiority and high malignancy. Reactivation of P16 by transferring the p16 gene into cancer cells induced cell G1 arrest and apoptosis (Chen et al., 2005), suggesting that the p16 gene may have a good future application in cancer gene therapy. The E2F promoter-regulated CRAd armed with the p16 gene, AdE2F-p16, was constructed (Ma et al., 2009). With the selective replication of AdE2F-p16 under the control of the E2F promoter, AdE2F-p16 expressed P16 with high levels in cancer cells. The improved antitumor efficacy of AdE2F-p16 was shown in human gastric cancer model in nude mice. The viral selective replication resulted in enhanced oncolysis, and p16 expression induced cancer cell apoptosis, suggesting that the combined effects led to the tumor growth inhibition in mouse models.

The p53 gene is one of the most important tumor suppressor gene. It plays an important role in cancer gene therapy, which has received preclinical validation by developing anticancer agents that specifically reactivate P53 function (Martins et al., 2006). To explore the efficacy of wild type p53 reactivation as a tumor therapy, some investigators demonstrated that 
restoring endogenous P53 expression in mice led to regression of autochthonous lymphomas through cellular apoptosis pathway and sarcomas through cellular senescence in mice, but without affecting normal tissues (Ventura et al., 2007). By RNA interference (RNAi) to conditionally regulate endogenous P53 expression in a mosaic mouse model of liver carcinoma, it was found that even brief reactivation of endogenous P53 in p53-deficient tumors could produce complete tumor regressions through the induction of a cellular senescence that was associated with differentiation and upregulation of inflammatory cytokines (Xue et al., 2007). These studies indicated that the p53-triggered tumor regression is not only due to the cellular apoptosis but the cellular senescence program, which is dependent on the tumor types. The transfer of wide type p53 gene is an important method to cure the p53-deficient cancers (Swisher \& Roth, 2002; Weill et al., 2000). A previous study demonstrated the enhanced antitumor effect of CRAd with the wild type p53 gene in the treatment of glioma (Van Beusechem et al., 2002). The tumor-specific CRAds carrying the wide type p53 gene, SG600-p53, can selectively replicate in tumor cells, whereas hardly replicated in normal cell lines, suggesting that SG600-p53 has a high selectivity to cancer cells and a low toxicity to normal cells. SG600-p53 expressed P53 with high efficiency in cancer cells. Both the high selectivity of viral replication and high efficiency of P53 expression ensured the efficient oncolytic effect and inhibition effect on cancer cells. In NCIH1299 tumor xenografts in nude mice, SG600-p53 achieved the significant antitumor efficacy. By pathological examination, administration of SG600-p53 resulted in cancer cell apoptosis. It is concluded that the CRAd carrying p53 gene, as a more potent and safer antitumor agent, could provide a new strategy for cancer biotherapy.

\section{Problems and prospects}

The achievements of success in adenovirus-based gene therapy bring forth new hope to treat cancer. Many countries worldwide invested heavily in cancer gene therapy, however, there are few products used in clinic because of their low efficacy. The differences between the in vitro and in vivo experiments, basic technology and clinical application should be further investigated. More worrying about the long-term toxicity of transgene vector also limits the wide utilization of gene therapy. These problems existed and exist, but they can not counteract the developments and prospects of gene therapy. The traditional strategies for cancer treatment, including surgery, chemotherapy and radiation, are difficult to eradicate the root of various cancers, the gene therapy absolutely searches for the roots cause of carcinogenesis, and corrects the genetic defects in transformed cells. Further investigations on the carcinogenesis mechanism, signal transduction and genetic characteristic of cancer cells will promote the development and breakthrough of cancer gene therapy in the future.

\section{References}

Abdul-Ghani, R., Ohana, P., Matouk, I., Ayesh, S., Ayesh, B., Laster, M., Bibi, O., Giladi, H., Molnar-Kimber, K., Sughayer, M. A., De Groot, N. \& Hochberg, A. (2000). Use of transcriptional regulatory sequences of telomerase (hTER and hTERT) for selective killing of cancer cells, Mol. Ther. 2(6): 539-544.

Ai, M. D., Li, L. L., Zhao, X. R., Wu, Y., Gong, J. P. \& Cao, Y. (2005). Regulation of survivin and CDK4 by Epstein-Barr virus encoded latent membrane protein 1 in nasopharyngeal carcinoma cell lines, Cell Res. 15(10):777-784. 
Alemany, R., Balagué, C. \& Curiel, D. T. (2000). Replicative adenoviruses for cancer therapy, Nat. Biotechnol. 18(7): 723-727.

Andrews, J. L., Kadan, M. J., Gorziglia, M. I., Kaleko, M. \& Connelly, S. (2001). Generation and characterization of E1/E2a/E3/E4-deficient adenoviral vectors encoding human factor VIII, Mol. Ther. 3(3):329-336.

Baratin, M., et al. (2001). Regression of primary hepatocarcinoma in cancer-prone transgenic mice by local interferon-gamma delivery is associated with macrophages recruitment and nitric oxide production, Cancer Gene Ther. 8(3):193-202.

Bartholomeusz, C., Itamochi, H., Yuan, L. X., Esteva, F. J., Wood, C. G., Terakawa, N., Hung, M. C. \& Ueno, N. T. (2005). Bcl-2 antisense oligonucleotide overcomes resistance to E1A gene therapy in a low HER2-expressing ovarian cancer xenograft model, Cancer Res. 65(18):8406-8413.

Bazan-Peregrino, M., Carlisle, R. C., Hernandez-Alcoceba, R., Iggo, R., Homicsko, K., Fisher, K. D., Halldén, G., Mautner, V., Shen, Y. \& Seymour, L. W. (2008). Comparison of molecular strategies for breast cancer virotherapy using oncolytic adenovirus, Hum. Gene Ther. 19(9): 873-886.

Belardelli, F. \& Gresser, I. (1996). The neglected role of type I interferon in the T-cell response: implications for its clinical use, Immunol. Today 17(8):369-372.

Berk, A. J. (2005). Recent lessons in gene expression, cell cycle control, and cell biology from adenovirus, Oncogene 24(52):7673-7685.

Biederer, C., Ries, S., Brandts, C. H. \& McCormick, F. (2002). Replication-selective viruses for cancer therapy, J. Mol. Med. 80(3):163-175.

Bischoff, J. R., Kirn, D. H., Williams, A., Heise, C., Horn, S., Muna, M., Ng, L., Nye, J. A., Sampson-Johannes, A., Fattaey, A. \& McCormick, F. (1996). An adenovirus mutant that replicates selectively in p53-deficient human tumor cells, Science 274(5286):373376.

Bruton, R. K., Pelka, P., Mapp, K. L., Fonseca, G. J., Torchia, J., Turnell, A. S., Mymryk, J. S. \& Grand, R. J. (2008). Identification of a second CtBP binding site in adenovirus 5 E1A conserved region 3, J. Virol. 82(17):8476-8486.

Bruton, R. K., Rasti, M., Mapp, K. L., Young, N., Carter, R. Z., Abramowicz, I. A., Sedgwick, G. G., Onion, D. F., Shuen, M., Mymryk, J. S., Turnell, A. S. \& Grand, R. J. (2007). Cterminal-binding protein interacting protein binds directly to adenovirus early region $1 \mathrm{~A}$ through its $\mathrm{N}$-terminal region and conserved region 3 , Oncogene 26(53):7467-7479.

Canepa, E. T., Scassa, M. E., Ceruti, J. M., Marazita, M. C., Carcagno, A. L., Sirkin, P. F. \& Ogara, M. F. (2007). INK4 proteins, a family of mammalian CDK inhibitors with novel biological functions, IUBMB Life 59(7):419-426.

Chen, C. T., Lin, J., Li, Q., Phipps, S. S., Jakubczak, J. L., Stewart, D. A., Skripchenko, Y., Forry-Schaudies, S., Wood, J., Schnell, C. \& Hallenbeck, P. L. (2000). Antiangiogenic gene therapy for cancer via systemic administration of adenoviral vectors expressing secretable endostatin, Hum. Gene Ther. 11(14):1983-1996.

Chen, F., Li, Y., Lu, Z., Gao, J. \& Chen, J. (2005). Adenovirus-mediated Ink4a/ARF gene transfer significantly suppressed the growth of pancreatic carcinoma cells, Cancer Biol. Ther. 4(12):1348-1354.

Chiu, C. P., Dragowska, W., Kim, N. W., Vaziri, H., Yui, J., Thomas, T. E., Harley, C. B. \& Lansdorp, P. M. (1996). Differential expression of tolemerase activity in 
hematopoietic progenitors from adult human bone marrow, Stem Cells 14(2):239248.

Cong, Y. S., Wen, J. \& Bacchetti, S. (1999). The human telomerase catalytic subunit hTERT: organization of the gene and characterization of the promoter, Hum. Mol. Genet. 8(1):137-142.

Connell, C. M., Wheatley, S. P. \& McNeish, I. A. (2008). Nuclear survivin abrogates multiple cell cycle checkpoints and enhances viral oncolysis, Cancer Res. 68(19):7923-7931.

Coqueret, O. (2002). Linking cyclins to transcriptional control, Gene 299(1-2):35-55.

Dvorak, H. F. \& Gresser, I. (1989). Microvascular injury in pathogenesis of interferoninduced necrosis of subcutaneous tumors in mice, J. Nat. Cancer Inst. 81(7):497-502.

Eickbush, T. H. (1997). Telomerase and retrotransposons: which came first? Science 277(5328): 911-912.

Fang, L., Huang, Y., Hu, X., Sun, L., He, X., Hu, H., Pu, Y., Cao, X., Luo, H., Pan, S., Gu, J. \& $\mathrm{Su}, \mathrm{C}$. (2009). A truncated minimal-E1a gene with potency to support adenoviral replication mediates antitumor activity by down-regulating Neu expression and preserving Rb function, Chem. Biol. Interact. 181(1):1-7.

Fang, L., Pu, Y. Y., Hu, X. C., Sun, L. J., Luo, H. M., Pan, S. K., Gu, J. Z., Cao, X. R. \& Su, C. Q. (2010). Antiangiogenesis gene armed tumor-targeting adenovirus yields multiple antitumor activities in human HCC xenografts in nude mice, Hepatol. Res. 40(2):216228.

Fathallah-Shaykh, H. M., Zhao, L. J., Kafrouni, A. I., Smith, G. M. \& Forman, J. (2000). Gene transfer of IFN-gamma into established brain tumors represses growth by antiangiogenesis, J. Immunol. 164(1):217-222.

Folkman, J. (1998). Antiangiogenic gene therapy, Proc. Natl. Acad. Sci. U S A 95(16):90649066.

Fueyo, J., Gomez-Manzano, C., Alemany, R., Lee, P. S., McDonnell, T. J., Mitlianga, P., Shi, Y. X., Levin, V. A., Yung, W. K. \& Kyritsis, A. P. (2000). A mutant oncolytic adenovirus targeting the $\mathrm{Rb}$ pathway produces antiglioma effect in vivo, Oncogene 19(1):2-12.

Fujimoto, K., Kyo, S., Takakura, M., Kanaya, T., Kitagawa, Y., Itoh, H., Takahashi, M. \& Inoue, M. (2000). Identification and characterization of negative regulatory elements of the human telomerase catalytic subunit (hTERT) gene promoter: possible role of MZF-2 in transcriptional repression of hTERT, Nucleic Acids Res. 28(13):2557-2562.

Ganly, I., Kirn, D., Eckhardt, G., Rodriguez, G. I., Soutar, D. S., Otto, R., Robertson, A. G., Park, O., Gulley, M. L., Heise, C., Von Hoff, D. D., Kaye, S. B. \& Eckhardt, S. G. (2000). A phase I study of Onyx-015, an E1B attenuated adenovirus, administered intratumorally to patients with recurrent head and neck cancer, Clin. Cancer Res. 6(3):798-806.

Gemin, A., Sweet, S., Preston, T. J. \& Singh, G. (2005). Regulation of the cell cycle in response to inhibition of mitochondrial generated energy, Biochem. Biophys. Res. Commun. 332(4):1122-1132.

Greenberg, R. A., O'Hagan, R. C., Deng, H., Xiao, Q., Hann, S. R., Adams, R. R., Lichtsteiner, S., Chin, L., Morin, G. B. \& Depinho, R. A. (1999). Telomerase reverse transcriptase gene is a direct target of c-Myc but is not functionally equivalent in cellular transformation, Oncogene 18(5):1219-1926. 
Gu, J., Andreeff, M., Roth, J. A. \& Fang, B. (2002). hTERT promoter induces tumor-specific Bax gene expression and cell killing in syngenic mouse tumor model and prevents systemic toxicity, Gene Ther. 9(1):30-37.

Gu, J., Kagawa, S., Takakura, M., Kyo, S., Inoue, M., Roth, J. A. \& Fang, B. (2000). Tumorspecific transgene expression from the human telomerase reverse transcriptase promoter enables targeting of the therapeutic effects of the bax gene to cancers, Cancer Res. 60(19):5359-5364.

Guadagni, F., Roselli, M., Schlom, J. \& Greiner, J. W. (1994). In vitro and in vivo regulation of human tumor antigen expression by human recombinant interferons: a review, Int. J. Biol. Markers 9(1):53-60.

Gunes, C., Lichtsteiner, S., Vasserot, A.P. \& Englert, C. (2000). Expression of the hTERT gene is regulated at the level of transcriptional initiation and repressed by Mad1, Cancer Res. 60(8):2116-2121.

Hale, T. K. \& Braithwaite, A. W. (1999). The adenovirus oncoprotein E1a stimulates binding of transcription factor ETF to transcriptionally activate the p53 gene, J. Biol. Chem. 274(34):23777-23786.

Haviv, Y. S., Blackwell, J. L., Li, H., Wang, M., Lei, X. \& Curiel, D. T. (2001). Heat shock and heat shock protein 70i enhance the oncolytic effect of replicative adenovirus, Cancer Res. 61(23):8361-8365.

Haviv, Y. S. \& Curiel, D. T. (2003). Engineering regulatory elements for conditionallyreplicative adeno-viruses, Curr. Gene Ther. 3(4):357-385.

He, X., Liu, J., Yang, C., Su, C., Zhou, C., Zhang, Q., Li, L., Wu, H., Liu, X., Wu, M. \& Qian, Q. (2010). 5/35 fiber-modified conditionally replicative adenovirus armed with p53 shows increased tumor-suppressing capacity to breast cancer cells. Hum. Gene Ther. doi:10.1089/hum.2010.058.

He, X., Su, C., Wang, X., Pan, X., Tu, Z., Gong, Y., Gao, J., Liao, Z., Jin, J., Wu, H., Man, X. \& Li, Z. (2009). E1B-55kD-deleted oncolytic adenovirus armed with canstatin gene yields an enhanced anti-tumor efficacy on pancreatic cancer, Cancer Lett. 285(1):8998.

Hermiston, T. W. \& Kuhn, I. (2002). Armed therapeutic viruses: strategies and challenges to arming oncolytic viruses with therapeutic genes, Cancer Gene Ther. 9(12):1022-1035.

Hernandez-Alcoceba, R., Pihalja, M., Qian, D. \& Clarke, M. F. (2002). New oncolytic adenoviruses with hypoxia- and estrogen receptor-regulated replication, Human Gene Ther. 13(14):1737-1750.

Hodes, R. (2001). Molecular targeting of cancer: telomeres as targets, Proc. Natl. Acad. Sci. U $S$ A 98(14):7649-7651.

Hong, S., Paulson, Q. X. \& Johnson, D. G. (2008). E2F1 and E2F3 activate ATM through distinct mechanisms to promote E1A-induced apoptosis, Cell Cycle 7(3):391-400.

Horikawa, I., Cable, P. L., Afshari, C. \& Barrett, J. C. (1999). Cloning and characterization of the promoter region of human telomerase reverse transcriptase gene, Cancer Res. 59(4):826-830.

Horikawa, I., Cable, P. L., Mazur, S. J., Appella, E., Afshari, C. A. \& Barrett, J. C. (2002). Downstream E-box-mediated regulation of the human telomerase reverse transcriptase (hTERT) gene transcription: evidence for an endogenous mechanism of transcriptional repression, Mol. Biol. Cell 13(8):2585-2597. 
Hu, H., Li, Z., Chen, J., Wang, D., Ma, J., Wang, W., Li, J., Wu, H., Li, L., Wu, M., Qian, Q., Chen, J. \& Su, C. (2010). P16 reactivation induces anoikis and exhibits antitumor potency by downregulating Akt/Survivin signaling in hepatocellular carcinoma cells, Gut doi:10.1136/gut.2010.220020.

Huang, T. G., Savontaus, M. J., Shinozaki, K., Sauter, B. V. \& Woo, S. L. C. (2003). Telomerase-dependent oncolytic adenovirus for cancer treatment, Gene Ther. 10(15):1241-1247.

Huang, X. F., Ren, W., Rollins, L., Pittman, P., Shah, M., Shen, L., Gu, Q., Strube, R., Hu, F. \& Chen, S. Y. (2003). A broadly applicable, personalized heat shock protein-mediated oncolytic tumor vaccine, Cancer Res. 63(21):7321-7329.

Irving, J., Wang, Z., Powell, S., O'Sullivan, C., Mok, M., Murphy, B., Cardoza, L., Lebkowski, J. S. \& Majumdar, A. S. (2004). Conditionally replicative adenovirus driven by the human telomerase promoter provides broad-spectrum antitumor activity without liver toxicity, Cancer Gene Ther. 11(3):174-185.

Itamochi, H., Kigawa, J., Kanamori, Y., Oishi, T., Bartholomeusz, C., Nahta, R., Esteva, F. J., Sneige, N., Terakawa, N. \& Ueno, N. T. (2007). Adenovirus type 5 E1A gene therapy for ovarian clear cell carcinoma: a potential treatment strategy, Mol. Cancer Ther. 6(1):227-235.

Jonasch, E. \& Haluska, F. G. (2001). Interferon in oncological practice: review of interferon biology, clinical applications, and toxicities, Oncologist 6(1):34-55.

Johnson, L., Shen, A., Boyle, L., Kunich, J., Pandey, K., Lemmon, M., Hermiston, T., Giedlin, M., McCormick, F. \& Fattaey, A. (2002). Selectively replicating adenoviruses targeting deregulated E2F activity are potent, systemic antitumor agents, Cancer Cell 1(4):325-337.

Kamphaus, G. D., Colorado, P. C., Panka, D. J., Hopfer, H., Ramchandran, R., Torre, A., Maeshima, Y., Mier, J. W., Sukhatme, V. P. \& Kalluri, R. (2000). Canstatin, a novel matrix-derived inhibitor of angiogenesis and tumor growth, J. Biol. Chem. 275(2):1209-1215.

Kawashima, T., Kagawa, S., Kobayashi, N., Shirakiya, Y., Umeoka, T., Teraishi, F., Taki, M., Kyo, S., Tanaka, N. \& Fujiwara, T. (2004). Telomerase-specific replication-selective virotherapy for human cancer, Clin Cancer Res. 10(1 Pt 1):285-292.

Khorana, A. A., Rosenblatt, J. D., Sahasrabudhe, D. M., Evans, T., Ladrigan, M., Marquis, D., Rosell, K., Whiteside, T., Phillippe, S., Acres, B., Slos, P., Squiban, P., Ross, M. \& Kendra, K. (2003). A phase I trial of immunotherapy with intratumoral adenovirusinterferon-gamma (TG1041) in patients with malignant melanoma, Cancer Gene Ther. 10(4):251-259.

Khuri, F. R., Nemunaitis, J., Ganly, I., Arseneau, J., Tannock, I. F., Romel, L., Gore, M., Ironside, J., Macdougall, R. H., Heise, C., Randlev, B., Gillenwater, A. M., Bruso, P., Kaye, S. B., Hong, W. K. \& Kirn, D. H. (2000). A controlled trial of intratumoral ONYX-015, a selectively-replicating adenovirus, in combination with cisplatin and 5-fluorouracil in patients with recurrent head and neck cancer, Nat. Med. 6(8):879885.

Kim, J., Kim, J. H., Choi, K. J., Kim, P. H. \& Yun, C. O. (2007). E1A- and E1B-Double mutant replicating adenovirus elicits enhanced oncolytic and antitumor effects, Hum. Gene Ther. 18(9):773-786. 
Kim, N. W., Piatyszek, M. A., Prowse, K. R., Harley, C. B., West, M. D., Ho, P. L., Coviello, G. M., Wright, W. E., Weinrich, S. L. \& Shay, J. W. (1994). Specific association of human telomerase activity with immortal cells and cancer, Science 266(5193):20112015.

Kirn, D., Martuza, R. L. \& Zwiebel, J. (2001). Replication-selective virotherapy for cancer: Biological principles, risk management and future directions, Nat. Med. 7(7):781787.

Koga, S., Hirohata, S., Kondo, Y., Komata, T., Takakura, M., Inoue, M., Kyo, S. \& Kondo, S. (2000). A novel telomerase-specific gene therapy: gene transfer of caspase-8 utilizing the human telomerase catalytic subunit gene promoter, Hum. Gene Ther. 11(10):1397-1406.

Kowalczyk, D. W., Wlazlo, A. P., Giles-Davis, W., Kammer, A. R., Mukhopadhyay, S. \& Ertl, H. C. (2003). Vaccine-induced CD8+ T cells eliminate tumors by a two-staged attack, Cancer Gene Ther. 10(12): 870-878.

Kurihara, T., Brough, D. E., Kovesdi, I. \& Kufe, D. W. (2000). Selectivity of a replicationcompetent adenovirus for human breast carcinoma cells expressing the MUC1 antigen, J. Clin. Invest. 106(6): 763-771.

Kyo, S., Takakura, M., Taira, T., Kanaya, T., Itoh, H., Yutsudo, M., Ariga, H. \& Inoue, M. (2000). Sp1 cooperates with c-Myc to activate transcription of the human telomerase reverse transcriptase gene (hTERT), Nucleic Acids Res. 28(3):669-677.

Lai, L. J., Xiao, X. \& Wu, J. H. (2007). Inhibition of corneal neovascularization with endostatin delivered by adeno-associated viral (AAV) vector in a mouse corneal injury model, J. Biomed. Sci. 14(3):313-22.

Lam, P. Y. \& Breakefield, X. O. (2001). Potential of gene therapy for brain tumors, Hum. Mol. Genet. 10(7):777-787.

Li, F., Yang, J., Ramnath, N., Javle, M. M. \& Tan, D. (2005). Nuclear or cytoplasmic expression of survivin: what is the significance? Int. J. Cancer 114(4):509-512.

Li, X., Liu, Y., Lee, S., Gardner, T., Jeng, M \& Kao, C. (2008). Prostate-restricted replicative adenovirus expressing human endostatin-angiostatin fusion gene exhibiting dramatic antitumor efficacy, Clin. Cancer Res. 14(1): 291-299.

Liao, Y., Yu, D. \& Hung, M. C. (2007). Novel approaches for chemosensitization of breast cancer cells: the E1A story, Adv. Exp. Med. Biol. 608:144-169.

Liu, F. \& Matsuura, I. (2005). Inhibition of Smad antiproliferative function by CDK phosphorylation. Cell Cycle 4(1):63-66.

Ma, J., He, X., Wang, W., Huang, Y., Chen, L., Cong, W., Gu, J., Hu, H., Shi, J., Li, L. \& Su, C. (2009). E2F promoter-regulated oncolytic adenovirus with p16 gene induces cell apoptosis and exerts antitumor effect on gastric cancer, Digest. Dis. Sci. 54(7):14251431.

Madhusudan, S., Tamir, A., Bates, N., Flanagan, E., Gore, M. E., Barton, D. P., Harper, P., Seckl, M., Thomas, H., Lemoine, N. R., Charnock, M., Habib, N. A., Lechler, R., Nicholls, J., Pignatelli, M. \& Ganesan, T. S. (2004). A multicenter Phase I gene therapy clinical trial involving intraperitoneal administration of E1A-lipid complex in patients with recurrent epithelial ovarian cancer overexpressing HER-2/neu oncogene, Clin. Cancer Res. 10(9): 2986-2996.

Martins, C. P., Brown-Swigart, L. \& Evan, G. I. (2006). Modeling the therapeutic efficacy of p53 restoration in tumors, Cell 127(7):1323-34. 
Merritt, R. E., Yamada, R. E., Crystal, R. G. \& Korst, R. J. (2004). Augmenting major histocompatibility complex class I expression by murine tumors in vivo enhances antitumor immunity induced by an active immunotherapy strategy, J. Thorac. Cardiovasc. Surg. 127(2):355-364.

Nagayama, Y., Nakao, K., Mizuguchi, H., Hayakawa, T. \& Niwa, M. (2003). Enhanced antitumor effect of combined replicative adenovirus and nonreplicative adenovirus expressing interleukin-12 in an immunocompetent mouse model, Gene Ther. 10(16):1400-1403.

Nakayama, J., Tahara, H., Tahara, E., Saito, M., Ito, K., Nakamura, H., Nakanishi, T., Tahara, E., Ide, T. \& Ishikawa, F. (1998). Telomerase activation by hTRT in human normal fibroblasts and hepatocellular carcinomas, Nat. Genet. 18(1):65-68.

Nanda, D., Vogels, R., Havenga, M., Avezaat, C. J., Bout, A. \& Smitt, P. S. (2001). Treatment of malignant gliomas with a replicating adenoviral vector expressing herpes simplex virus-thymidine kinase, Cancer Res. 61(24):8743-8750.

Narazaki, M. \& Tosato, G. (2006). Canstatin: an inhibitor of angiogenesis and tumor growth revisited, Cancer J. 12(2):110-112.

Nemajerova, A., Talos, F., Moll, U. M. \& Petrenko, O. (2008). Rb function is required for E1A-induced S-phase checkpoint activation, Cell Death Differ. 15(9):1440-1449.

Ning, T., Yan, X., Lu, Z. J., Wang, G. P., Zhang, N. G., Yang, J. L., Jiang, S. S., Wu, Y., Yang, L., Guan, Y. S. \& Luo, F. (2009). Gene therapy in orthotopic lung cancer murine model with angiogenesis inhibitor, endostatin, Hum. Gene Ther. 20(2):103-111.

Nowak, J., Januszkiewicz, D., Lewandowski, K., Nowicka-Kujawska, K., Pernak, M., Rembowska, J., Nowak, T. \& Wysocki, J. (2003). Activity and expression of human telomerase in normal and malignant cells in gastric and colon cancer patients, Eur. J. Gastroenterol. Hepatol.15(1):75-80.

Ohashi, M., Kanai, F., Tateishi, K., Taniguchi, H., Marignani, P. A., Yoshida, Y., Shiratori, Y, Hamada, H. \& Omata, M. (2001). Target gene therapy for alpha-fetoproteinproducing hepatocellular carcinoma by E1B55k-attenuated adenovirus, Biochem. Biophys. Res. Commun. 282(2):529-535.

Ortega, S., Malumbres, M. \& Barbacid, M. (2002). Cyclin D-dependent kinases, INK4 inhibitors and cancer, Biochim. Biophys. Acta 1602(1):73-87.

Osaki, T., Tanio, Y., Tachibana, I., Hosoe, S., Kumagai, T., Kawase, I., Oikawa, S. \& Kishimoto, T. (1994). Gene therapy for carcinoembryonic antigen-producing human lung cancer cells by cell type-specific expression of herpes simplex virus thymidine kinase gene, Cancer Res. 54(20):5258-5261.

Ouchi, M., Kawamura, H., Urata, Y. \& Fujiwara, T. (2009). Antiviral activity of cidofovir against telomerase-specific replication-selective oncolytic adenovirus, OBP-301 (Telomelysin), Invest. New Drugs 27(3):241-245.

Peng, X. Y., Won, J. H., Rutherford, T., Fujii, T., Zelterman, D., Pizzorno, G., Sapi, E., Leavitt, J., Kacinski, B., Crystal, R., Schwartz, P. \& Deisseroth, A. (2001). The use of the Lplastin promoter for adenoviral-mediated, tumor-specific gene expression in ovarian and bladder cancer cell lines, Cancer Res. 61(11): 4405-4413.

Peyregne, V., Quash, G., Isaac, S., Chantepie, J., Akiba, H., Scoazec, J. Y. \& Gilly, F. N. (2004). Survival after gamma interferon intratumoral injections in a model of hepatocarcinoma, Hepatogastroenterology 51(58):1115-1120. 
Poole, J. C., Andrews, L. G. \& Tollefsbol, T. O. (2001). Activity, function, and gene regulation of the catalytic subunit of telomerase (hTERT), Gene 269(1-2):1-12.

Post, D. E., Khuri, F. R., Simons, J. W. \& van Meir, E. G. (2003). Replicative oncolytic adenoviruses in multimodal cancer regimens, Hum. Gene Ther. 14(10):933-946.

Radke, J. R., Siddiqui, Z. K., Miura, T. A., Routes, J. M. \& Cook, J. L. (2008). E1A oncogene enhancement of caspase-2-mediated mitochondrial injury sensitizes cells to macrophage nitric oxide-induced apoptosis, J. Immunol. 180(12):8272-8279.

Ramachandra, M., Rahman, A., Zou, A., Vaillancourt, M., Howe, J. A., Antelman, D., Sugarman, B., Demers, G. W., Engler, H., Johnson, D. \& Shabram, P. (2001). Reengineering adenovirus regulatory pathways to enhance oncolytic specificity and efficacy, Nat. Biotechnol. 19(11):1035-1041.

Ring, C. J. (2002). Cytolytic viruses as potential anti-cancer agents, J. Gen. Virol. 83(Pt 3):491502.

Rodriguez, R., Schuur, E. R., Lim, H. Y., Henderson, G. A., Simons, J. W. \& Henderson, D. R. (1997). Prostate attenuated replication competent adenovirus (ARCA) CN706: a selective cytotoxic for prostate-specific antigen-positive prostate cancer cells, Cancer Res. 57(13):2559-2563.

Sánchez-Prieto, R., Quintanilla, M., Cano, A., Leonart, M. L., Martin, P., Anaya, A. \& Ramón y Cajal, S. (1996). Carcinoma cell lines become sensitive to DNA-damaging agents by the expression of the adenovirus E1A gene, Oncogene 13(5):1083-1092.

Saretzki, G., Petersen, S., Petersen, I., Kolble, K. \& Von Zglinicki, T. (2002). hTERT gene dosage correlates with telomerase activity in human lung cancer cell lines, Cancer Lett. 176(1):81-91.

Shay, J. W. \& Bacchetti, S. (1997). A survey of telomerase activity in human cancer, Eur. J. Cancer 33(5):787-791.

Singh, R. K., Gutman, M., Bucana, C. D., Sanchez, R., Llansa, N. \& Fidler, I. J. (1995). Interferons alpha and beta down-regulate the expression of basic fibroblast growth factor in human carcinomas, Proc. Natl. Acad. Sci. U S A 92(10):4562-4566.

Steele, T. A. (2000). Recent developments in the virus therapy of cancer, Proc. Soc. Exp. Biol. Med. 223(2):118-127.

Su, C., Cao, H., Tan, S., Huang, Y., Jia, X., Jiang, L., Wang, K., Chen, Y., Long, J., Liu, X., Wu, M., Wu, X. \& Qian, Q. (2008a). Toxicology profiles of a novel p53-armed replication-competent oncolytic adenovirus in rodents, felids and nonhuman primates, Toxicol. Sci. 106(1):242-250.

Su, C., Na, M., Chen, J., Wang, X., Liu, Y., Wang, W., Zhang, Q., Li, L., Long, J., Liu, X., Wu, M., Fan, X. \& Qian, Q. (2008b). Gene-viral cancer therapy using dual-regulated oncolytic adenovirus with antiangiogenesis gene for increased efficacy, Mol. Cancer Res. 6(4):568-575.

Su, C., Peng, L., Sham, J., Wang, X., Zhang, Q., Chua, D., Liu, C., Cui, Z., Xue, H., Wu, H., Yang, Q., Zhang, B., Liu, X., Wu, M. \& Qian, Q. (2006a). Immune gene-viral therapy with triplex efficacy mediated by oncolytic adenovirus carrying interferon-gamma gene yields efficient antitumor activity in immunodeficient and immunocompetent mice, Mol. Ther. 13(5):918-927.

Su, C., Sham, J., Xue, H., Wang, X., Chua, D., Cui, Z., Peng, L., Li, L., Jiang, L., Wu, M. \& Qian, Q. (2004). Potent antitumoral efficacy of a novel replicative adenovirus 
cnhk300 targeted to the telomerase-positive cancer cells, J. Cancer Res. Clin. Oncol. 130(10):591-603.

Su, C., Wang, X., Chen, J., Liu, Y., Wang, W., Li, L., Wu, M. \& Qian, Q. (2006b). Antitumor activity of an hTERT promoter-regulated tumor-selective oncolytic adenovirus in human hepatocellular carcinoma, World J. Gastroenterol. 12(47):7613-7620.

Swisher, S. G. \& Roth, J. A. (2002). p53 Gene therapy for lung cancer, Curr. Oncol. Rep. 4(4):334-40.

Takakura, M., Kyo, S., Kanaya, T., Hirano, H., Takeda, J., Yutsudo, M. \& Inoue, M. (1999). Cloning of human telomerase catalytic subunit (hTERT) gene promoter and identification of proximal core promoter sequences essential for transcriptional activation in immortalized and cancer cells, Cancer Res. 59(3):551-557.

Thomas, C. E., Ehrhardt, A. \& Kay, M. A. (2003). Progress and problems with the use of viral vectors for gene therapy, Nat. Rev. Genet. 4(5):346-358.

Tsukuda, K., Wiewrodt, R., Molnar-Kimber, K., Jovanovic, V. P. \& Amin, K. M. (2002). An E2F-responsive replication-selective adenovirus targeted to the defective cell cycle in cancer cells: potent antitumoral efficacy but no toxicity to normal cell, Cancer Res. 62(12):3438-3447.

Van Beusechem, V. W., van den Doel, P. B., Grill, J., Pinedo, H. M. \& Gerritsen, W. R. (2002). Conditionally replicative adenovirus expressing p53 exhibits enhanced oncolytic potency, Cancer Res. 62(21):6165-6171.

Ventura, A., Kirsch, D. G., McLaughlin, M. E., Tuveson, D. A., Grimm, J., Lintault, L., Newman, J., Reczek, E. E., Weissleder, R. \& Jacks, T. (2007). Restoration of p53 function leads to tumour regression in vivo, Nature 445(7128):606-607.

Wang, X., Su, C., Cao, H., Li, K., Chen, J., Jiang, L., Zhang, Q., Wu, X., Jia, X., Liu, Y., Wang, W., Liu, X., Wu, M. \& Qian, Q. (2008). A novel triple-regulated oncolytic adenovirus carrying p53 gene exerts potent antitumor efficacy on common human solid cancers, Mol. Cancer Ther. 7(6):1598-1603.

Weill, D., Mack, M., Roth, J., Swisher, S., Proksch, S., Merritt, J. \& Nemunaitis, J. (2000). Adenoviral-mediated p53 gene transfer to non-small cell lung cancer through endobronchial injection, Chest 118(4):966-970.

Weinrich, S. L., Pruzan, R., Ma, L., Ouellette, M., Tesmer, V. M., Holt, S. E., Bodnar, A. G., Lichtsteiner, S., Kim, N. W., Trager, J. B., Taylor, R. D., Carlos, R., Andrews, W. H., Wright, W. E., Shay, J. W., Harley, C. B. \& Morin, G. B. (1997). Reconstitution of human telomerase with the template RNA component hTR and the catalytic protein subunit hTRT, Nat. Genet. 17(4):498-502.

Wirth, T., Zender, L., Schulte, B., Mundt, B., Plentz, R., Rudolph, K. L., Manns, M., Kubicka, S., Kühnel, F. (2003). A telomerease-dependent conditionally replicating adenovirus for selective treatment of cancer, Cancer Res. 63(12):3181-3188.

Wu, M., Hussain, S., He, Y. H., Pasula, R., Smith, P. A. \& Martin, W. J. 2nd. (2001). Genetically engineered macrophages expressing IFN-gamma restore alveolar immune function in scid mice, Proc. Natl. Acad. Sci. U S A 98(25):14589-14594.

Xu, D., Wang, Q., Gruber, A., Bjorkholm, M., Chen, Z., Zaid, A., Selivanova, G., Peterson, C., Wiman, K. G. \& Pisa, P. (2000). Downregulation of telomerase reverse transcriptase mRNA expression by wild type p53 in human tumor cells, Oncogene 19(45):51235133. 
Xue, W., Zender, L., Miething, C., Dickins, R. A., Hernando, E., Krizhanovsky, V., CordonCardo, C. \& Lowe, S. W. (2007). Senescence and tumour clearance is triggered by p53 restoration in murine liver carcinomas, Nature 445(7128): 656-660.

Yang, C., Cirielli, C., Capogrossi, M. C. \& Passaniti, A. (1995). Adenovirus-mediated wildtype p53 expression induces apoptosis and suppresses tumorigenesis of prostatic tumor cells. Cancer Res. 55(19):4210-4213.

Yang, Z. R., Wang, H. F., Zhao, J., Peng, Y. Y., Wang, J., Guinn, B. A. \& Huang, L. Q. (2007). Recent developments in the use of adenoviruses and immunotoxins in cancer gene therapy, Cancer Gene Ther. 14(7):599-615.

Yoo, G. H., Hung, M. C., Lopez-Berestein, G., LaFollette, S., Ensley, J. F., Carey, M., Batson, E., Reynolds, T. C. \& Murray, J. L. (2001). Phase I trial of intratumoral liposome E1A gene therapy in patients with recurrent breast and head and neck cancer, Clin. Cancer Res. 7(5):1237-1245.

$\mathrm{Yu}$, W. \& Fang, H. (2007). Clinical trials with oncolytic adenovirus in China, Curr. Cancer Drug Targets 7(2):141-148.

Yui, J., Chiu, C. P. \& Lansdorp, P. M. (1998). Telomerase activity in candidate stem cells from fetal liver and adult bone marrow, Blood 91(9):3255-3262.

Zhang, J. F., Hu, C., Geng, Y., Selm, J., Klein, S. B., Orazi, A. \& Taylor, M. W. (1996). Treatment of a human breast cancer xenograft with an adenovirus vector containing an interferon gene results in rapid regression due to viral oncolysis and gene therapy, Proc. Natl. Acad. Sci. U S A 93(9):4513-4518.

Zou, W., Luo, C., Zhang, Z., Liu, J., Gu, J., Pei, Z., Qian, C. \& Liu, X. (2004). A novel oncolytic adenovirus targeting to telomerase activity in tumor cells with potent, Oncogene 23(2):457-464. 


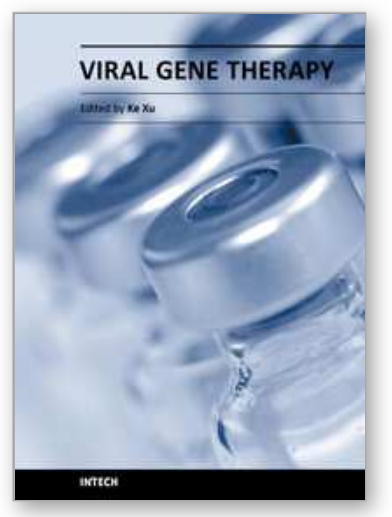

\author{
Viral Gene Therapy \\ Edited by Dr. Ke Xu
}

ISBN 978-953-307-539-6

Hard cover, 450 pages

Publisher InTech

Published online 20, July, 2011

Published in print edition July, 2011

The development of technologies that allow targeting of specific cells has progressed substantially in recent years for several types of vectors, particularly viral vectors, which have been used in $70 \%$ of gene therapy clinical trials. Particular viruses have been selected as gene delivery vehicles because of their capacities to carry foreign genes and their ability to efficiently deliver these genes associated with efficient gene expression. This book is designed to present the most recent advances in viral gene therapy

\title{
How to reference
}

In order to correctly reference this scholarly work, feel free to copy and paste the following:

Changqing Su (2011). Adenovirus-Based Gene Therapy for Cancer, Viral Gene Therapy, Dr. Ke Xu (Ed.), ISBN: 978-953-307-539-6, InTech, Available from: http://www.intechopen.com/books/viral-genetherapy/adenovirus-based-gene-therapy-for-cancer

\section{INTECH}

open science | open minds

\author{
InTech Europe \\ University Campus STeP Ri \\ Slavka Krautzeka 83/A \\ 51000 Rijeka, Croatia \\ Phone: +385 (51) 770447 \\ Fax: +385 (51) 686166 \\ www.intechopen.com
}

\author{
InTech China \\ Unit 405, Office Block, Hotel Equatorial Shanghai \\ No.65, Yan An Road (West), Shanghai, 200040, China \\ 中国上海市延安西路65号上海国际贵都大饭店办公楼405单元 \\ Phone: +86-21-62489820 \\ Fax: +86-21-62489821
}


(C) 2011 The Author(s). Licensee IntechOpen. This chapter is distributed under the terms of the Creative Commons Attribution-NonCommercialShareAlike-3.0 License, which permits use, distribution and reproduction for non-commercial purposes, provided the original is properly cited and derivative works building on this content are distributed under the same license. 